\title{
JENIS POHON PAKAN KUKANG JAWA (Nycticebus javanicus) DI TAMAN WISATA ALAM GUNUNG TAMPOMAS
}

\section{Species of Feeding Tree of Javan Slow loris (Nycticebus javanicus) in Gunung Tampomas Natural Tourism Park}

\author{
Rendi Nurhadi', Asep Purwanto ${ }^{2)}$ \\ 1) Perumahan Hegarmanah Indah HG 2, Desa Hegarmanah, Kec. Cikacung- \\ Bandung; nurhadirendi@gmail.com \\ 2) Fakultas Kehutanan Universitas Winaya Mukti; aseppurwanto870@gmail.com
}

\section{Disetujui 30 September 2020/Diterima10 Oktober 2020}

\begin{abstract}
Javan Slow Loris (Nycticebus javanicus) is one of endemic species of Java island that one of endangered species. Data and research of Nycticebus javanicus is still low. So, this condition difficult to it conservation. Existing of Nycticebus javanicus depend on forest vegetation including species of feeding tree. The method of research by plot of tree food observation, niche analysis that focus of feeding activity and part of feed. The result of research are 17 species of tree, there are aren (Arenga pinnata), bamboo (Bambusa vulgaris), bisoro (Ficus leificarva), hamirung (Vernonia arborea), huru leueur (Phoebe excelsa), kaliandra (Calliandra calotyrsus), kiteja (Parinari sumatrana), kitembaga (Eugenia cuprea), kibanen (Criyteronia paniculata), kiara (Ficus altisima), kipait (Tithonia diversifolia), kisampang (Evodia latifolia), kilaki (Adina fagifolia), nangsi (Villebrunea rubescens), sempur (Dillenia indica), teureup (Artocarpus elastic), and tangkil (Gnetum gnenom). Part of feed is fruit, leef, sprout, and flower.
\end{abstract}

Keyword: Nycticebus javanicus, Gunung Tampomas, Feeding tree

\section{PENDAHULUAN}

Kukang jawa (Nycticebus javanicus) merupakan salah satu satwa endemik Pulau Jawa yang terdaftar sebagai satwa terancam punah. Data kondisi kukang jawa terkini sangat minim, sehingga menyulitkan dalam upaya konservasi atau penyelamatannya. Hal ini ditambah kenyataan bahwa kukang merupakan satwa primata kedua yang paling diminati sebagai satwa peliharaan, sehingga banyak 
diperjual belikan dan menyebabkan populasinya sampai saat ini semakin berkurang.

Kategori kukang jawa berdasarkan data IUCN (International Union for Conservation of Nature) merupakan satwa yang berstatus kritis (Critically Endangered) dan masuk ke dalam 20 jenis primata di dunia yang paling terancam punah tahun 2014-2016. Status ini diperkuat oleh daftar yang dikeluarkan oleh CTES (Conservation on Internasional Trade of Endangered) dan mengubah status kukang dari Apendiks II menjadi Apendiks I yaitu flora dan fauna yang jumlahnya sudah sangat sedikit dan memiliki kecenderungan untuk punah.

Hasil beberapa penelitian menyatakan bahwa sebaran kukang jawa lebih banyak dan mudah ditemukan di area perkebunan atau lahan rakyat dari pada hutan alami. Seperti di beberapa wilayah kabupaten ini kukang ditemukan di lahan perkebunan dan pertanian, yaitu di wilayah Kabupaten Rangkas Bitung dan Malimping, Kabupaten Bogor (Gunung Salak dan Bodogol), Kabupaten Sukabumi (Gunung Halimun dan Bodogol), Kabupaten Garut, Kabupaten Tasikmalaya, Kabupaten Sumedang, dan Kabupaten Ciamis (Winarti 2003; 2011; Wirdateti et al. 2004; 2011; Wirdateti dan Dahrudin 2008;Pambudi, 2008).

Selain di wilayah kabupaten di atas, salah satu wilayah kukang yang ditemukan pada talun atau kebun masyarakat juga terdapat di Kabupaten Sumedang. Menurut Widiana et.al., (2013) kukang jawa ditemukan di talun yang berada di Desa Sindulang, Kecamatan Cimanggung. Di Kabupaten Sumedang juga berdasarkan hasil wawancara terdapat di Taman Wisata Alam (TWA) Gunung Tampomas. Kawasan hutan Gunung Tampomas merupakan merupakan kawasan konservasi berupa Taman Wisata Alam yang ditetapkan berdasarkan Surat Keputusan Menteri Pertanian : 423/Kpts/Um/7/1979, tanggal 5 Juli 1979 dengan areal luas \pm 1.250 Ha. Hasil wawancara kepada pihak pengelola TWA Gunung Tampomas bahwa kukang jawa merupakan salah satu satwa yang banyak ditemukan di kawasan tersebut, terutama blok Lebak Jero dan blok Malakadatar yang merupakan daerah perbatasan antara kawasan TWA dan lahan pertanian milik warga. Selain itu masih belum ada data mengenai jumlah populasi dan karakteristik habitat yang disukai kukang jawa, sehingga belum menemukan jawaban mengapa kukang jawa hanya ada di kedua blok tersebut.

Kukang jawa merupakan satwa yang bersifat omnivora dengan komposisi jenis pakannya, yaitu bunga, daun, buah, pucuk dan sisanya bagian dari tumbuhan atau serangga. Selain itu kukang jawa merupakan binatang nokturnal dan arboreal, sehingga hal ini menunjukan bahwa kehidupan kukang jawa sangat tergantung pada keberadaan vegetasi hutan, termasuk jenis pohon pakan. Pohon pakan ini sangat berperan dalam mendukung keberlangsungan hidup bagi kukang jawa yang tidak diketahui pada kawasan tersebut. Kondisi-kondisi demikian, perlu adanya 
penelitian mengenai jenis pakan kukang jawa di kedua blok TWA Gunung Tampomas tersebut, karena dengan mengetahui jenis pakan kukang jawa yang terdapat di TWA Gunung Tampomas ini akan membantu mengurangi kepunahan populasi kukang jawa sebagai satwa endemik Pulau Jawa dengan melestarikan jenis pakan tersebut.

\section{METODE PENELITIAN}

Penelitian ini dilaksanakan pada Blok Lebak Jero dengan luas sekitar 13.81 Ha dan Blok Malakadatar dengan luas sekitar 73.21 Ha di kawasan TWA Gunung Tampomas, Kabupaten Sumedang. Alat yang digunakan dalam penelitian ini adalah kompas untuk menentukan arah, tali rapia, jam tangan untuk mencatat waktu, alat tulis untuk menulis data, binokuler sebagai alat bantu untuk melihat subjek dengan jelas, GPS (Global Positioning System) untuk menentukan titik kordinat, kamera untuk dokumentasi di lapangan. Bahan atau objek penelitian yaitu kukang jawa yang sedang melakukan aktivitas makan di 9 plot ditemukannya kukang jawa.

Jenis data yang dikumpulkan: (1) Data Primer, meliputi data jenis pakan, bagian yang dimakan (daun, bunga, buah, dan pucuk), serta keterangan pendukung lainnya. (2) Data Sekunder, meliputi keadaan umum lokasi penelitian yang terdiri letak, luas kawasan, topografi, pengelolan kawasan TWA Gunung Tampomas dan data jenis pakan kukang jawa dari beberapa referensi dan wawancara kepada pengelola TWA Gunung Tampomas dan masyarakat sekitar.

Metode pengumpulan data dengan pembuatan plot pengamatan jenis pakan kukang jawa menggunakan analisis ruang, dimana dalam analisis ruang ini terfokuskan pada aktivitas kukang jawa saat makan dengan mengamati langsung jenis pakan dan bagian yang dimakan oleh kukang jawa. Plot yang diamati dalam penelitian di lapangan dengan menggunakan analisis ruang berupa plot 3 dimensi, dimana dengan menggunakan plot 3 dimensi tersebut dapat dilihat satwa makan dalam kondisi apapun, selain itu plot yang dibuat tidak selalu dalam plot analisis vegetasi. Hasil dari pengamatan jenis pakan kukang jawa dicatat dalam tallysheet dan dilakukan sebanyak 20 kali ulangan, yaitu 10 kali pengamatan malam dan 10 kali pengamatan siang hari yang bertujuan untuk mengecek hasil pengamatan malam. Analisis data dilakukan dengan tabulasi dan analisis deskriptif mengenai hasil yang ditemukan di lapangan dan perbandingan dengan beberapa referensi. 


\section{HASIL DAN PEMBAHASAN}

\section{Jumlah Jenis Pakan Kukang Jawa}

Jenis pakan kukang jawa (Nycticebus javanicus) di kawasan TWA Gunung Tampomas dari hasil pengamatan pada 9 plot yang ditemukan kukang jawa terdiri dari 17 jenis dari tingkat pohon dan dari 13 famili (Tabel 1). Hal ini dapat diartikan bahwa jenis pakan kukang jawa sangat beragam dan jika dilihat dari tingkatan pohon sesuai dengan pola hidup kukang jawa yang bersifat arboreal, sehingga jenis sumber pakan yang ditemukan dan dimanfaatkan oleh kukang jawa berupa vegetasi tingkat pohon.

Tabel 1. Jenis pakan kukang jawa secara keseluruhan di TWA Gunung Tampomas

\begin{tabular}{clll}
\hline No & \multicolumn{1}{c}{ Nama Lokal } & \multicolumn{1}{c}{ Nama Ilmiah } & Famili \\
& & & \\
\hline 1 & Aren & Arenga pinnata & Arecaceae \\
2 & Bambu & Bambusa vulgaris & Poaceae \\
3 & Bisoro & Ficus leificarva & Moraceae \\
4 & Hamirung & Vernonia arborea & Asteraceae \\
5 & Huru leueur & Phoebe excelsa & Lauraceae \\
6 & Kaliandra & Calliandra calotyrsus & Fabaceae \\
7 & Kiteja & Parinari sumatrana & Lauraceae \\
8 & Kitambaga & Eugenia cuprea & Myrtaceae \\
9 & Kibanen & Criyteronia paniculata & Crypteroniaceae \\
10 & Kiara & Ficus altisima & Moraceae \\
11 & Kipait & Tithonia diversifolia & Asteracea \\
12 & Kisampang & Evodia latifolia & Rutaceae \\
13 & Kilaki & Adina fagifolia & Rubiaceae \\
14 & Nangsi & Villebrunea rubescens & Urticaceae \\
15 & Sempur & Dillenia indica & Dilleniaceae \\
16 & Teureup & Artocarpus elastic & Moraceae \\
17 & Tangkil & Gnetum gnenom & Gnetaceae \\
\hline
\end{tabular}

Jumlah jenis pakan kukang jawa di TWA Gunung Tampomas yang terdapat 17 jenis diperkirakan masih kurang ketersediannya terlihat variasi jenisnya dibandingkan dengan jenis pakan kukang di lokasi lain. Seperti halnya dari hasil inventarisasi vegetasi pakan kukang yang masih satu famili kukang jawa dan masih di kawasan hutan konservasi, yaitu $N$. menagensis dari hasil pengamatan langsung maupun informasi dari penduduk sekitar memperlihatkan sedikitnya 33 spesies tumbuhan dari 21 famili di hutan lindung pegunungan Merratus Kalimantan Selatan dan sedikitnya 44 spesies dari 17 famili di hutan produksi rakyat Pasir Panjang Kalimantan Tengah (Wirdateti 2005; Dahrudin \& Wirdateti 2008).

Hal ini berbeda dengan Romdhoni et.al. (2018) yang melakukan penelitian di talun Desa Cipaganti, Garut jenis pohon pakan yang dimanfaatkan oleh kukang jawa hanya 7 jenis, yaitu alpukat (Persea americana), bambu surat ( $G$. pseudoarundinaceae), bambu temen (G. verticillata), jiengjen (A. deccurens), kaliandra merah (C. calaothyrsus), kayu putih (M. leucadendra), dan suren (Toona sureni). Jika dibandingkan dengan Romdhoni et.al (2018), maka kukang jawa 
yang berada di TWA Gunung Tampomas masih lebih tinggi jenis pohon pakan yang dimanfaatkannya. Hal ini diperkirakan karena di talun merupakan jenis pohon yang memang sengaja ditanam, sedangkan TWA Gunung Tampomas merupakan kawasan hutan konservasi yang seharusnya memiliki jenis lebih banyak lagi. Oleh karena itu, diperlukan pengkayaan jenis pohon kukang sehingga kukang dapat terjaga ke lestariannya dan tidak ke luar kawasan yang dikahwatirkan memudahkan untuk terjadinya perburuan liar.

Kondisi kurangnya variasi jenis ini menyebabkan kukang jawa di TWA Gunung Tampomas lebih banyak ditemukan di luar kawasan pada talun/kebun masyarakat. Hal ini dibuktikan pada saat penelitian kukang jawa yang ada dilokasi penelitian sering ke luar kawasan juga, yaitu ke perkebunan warga untuk mencari makan seperti pada musim buah-buahan. Hal diduga disebabkan oleh kurangnya variasi jenis pakan yang ada di dalam kawasan dan pakan diperkebunan lebih bervariatif dari pada didalam kawasan. Hal ini sesuai dengan pernyataan yang dikemukakan oleh Rowe (1996) bahwa ketersediaan sumber pakan dan aktifitas manusia berpengaruh terhadap daerah jelajah. Kukang jawa di lokasi penelitian memiliki kemungkinan daerah jelajah hingga keluar area desa. Selain itu, jumlah perjumpaan dan populasi yang tinggi di tipe habitat yang tidak stabil kemungkinan hanya bersifat sementara (Nekaris et al. 2008).

\section{Sebaran Jenis Pakan Kukang dan Bagian yang Dimakan Sebaran Jenis Pakan}

Jika dilihat dari sebaran jenis pakan terdapat perbedaan pada pada setiap plot pengamatan, seperti pada plot 1 sampai 4, sedangkan pada plot 5 sampai 9 jenis pakannya hampir sama dengan pada plot 1, 2, dan 4 (Tabel 2). Kondisi ini dapat diartikan bahwa kondisi jenis pakan tidak menyebar sehingga variasi jenis pada setiap plot sangat rendah, sehingga kukang sering menjelajah ke luar kawasan untuk mencari pakan di perkebunan masyarakat.

Tabel 2. Jenis pakan kukang jawa di TWA Gunung Tampomas

\begin{tabular}{lllcl}
\hline $\begin{array}{c}\text { No } \\
\text { Plot }\end{array}$ & Koordinat UTM & Nama Lokal & $\begin{array}{c}\sum_{\text {Individu }} \\
\text { Bagian yang dimakan }\end{array}$ \\
\hline 1 & 827273,9254530 & Aren & 3 & Daun \\
& & Bambu & 3 & Daun, pucuk \\
& & Bisoro & 2 & Buah \\
2 & \multirow{3}{*}{827370,9254389} & Hamirung & 2 & Pucuk \\
& & Huru leueur & 1 & Buah \\
& & Kaliandra & 2 & Daun \\
3 & \multirow{2}{*}{827285,9254206} & Kiteja & 2 & Buah \\
& & Kitambaga & 2 & Daun, pucuk \\
& & Kibanen & 2 & Pucuk \\
& & Kiara & 3 & Buah. Daun \\
& & Kipait & 1 & Daun \\
& & Kisampang & 2 & Pucuk \\
\hline
\end{tabular}




\begin{tabular}{|c|c|c|c|c|}
\hline $\begin{array}{c}\text { No } \\
\text { Plot }\end{array}$ & Koordinat UTM & Nama Lokal & $\sum_{\text {Individu }}$ & Bagian yang dimakan \\
\hline \multirow[t]{5}{*}{4} & 826836,9254061 & Kilaki & 2 & Buah \\
\hline & & Nangsi & 1 & Buah, pucuk \\
\hline & & Sempur & 3 & Bunga, pucuk \\
\hline & & Teureup & 1 & Buah \\
\hline & & Tangkil & 1 & Pucuk \\
\hline \multirow[t]{4}{*}{5} & 826762,9254248 & Aren & 2 & Daun \\
\hline & & Bambu & 4 & Daun, pucuk \\
\hline & & Bisoro & 3 & Buah \\
\hline & & Kiara & 2 & Buah, daun \\
\hline \multirow[t]{4}{*}{6} & 826417,9253785 & Kiara & 3 & Buah. Daun \\
\hline & & Kipait & 1 & Daun \\
\hline & & Bambu & 3 & Daun, pucuk \\
\hline & & Kaliandra & 2 & Daun \\
\hline \multirow[t]{4}{*}{7} & 826420,9254049 & Aren & 2 & Daun \\
\hline & & Bambu & 3 & Daun, pucuk \\
\hline & & Kaliandra & 2 & Daun \\
\hline & & Kiara & 2 & Buah, daun \\
\hline \multirow[t]{4}{*}{8} & 826493,9253922 & Bambu & 2 & Daun, pucuk \\
\hline & & Bisoro & 2 & Buah \\
\hline & & Hamirung & 2 & Pucuk \\
\hline & & Teureup & 1 & Buah \\
\hline \multirow[t]{4}{*}{9} & 826421,9254048 & Aren & 1 & Daun \\
\hline & & Bambu & 3 & Daun, pucuk \\
\hline & & Kiara & 2 & Buah. Daun \\
\hline & & Sempur & 1 & Bunga, pucuk \\
\hline
\end{tabular}

Jenis pakan kukang jawa pada plot 1 ditemukan 4 jenis tumbuhan, aren, bambu, bisoro, dan hamirung. Jenis pakan kukang jawa pada plot 2 juga ditemukan 4 jenis tumbuhan, tetapi berbeda dengan plot 1, yaitu terdiri dari huru leueur, kaliandra, kiteja, dan kitambaga. Jenis pakan pada plot 3 terdiri dari 4 jenis dan berbeda dengan plot 1 dan 2, yaitu kibanen, kiara, kipait, dan kisampang. Begitu juga dengan plot 4 ini masih berbeda komposisi jenisnya dengan plot 1,2, dan 3, yaitu kilaki, nangsi, sempur, teureup, dan tangkil. Sedangkan pada plot 5 sampai 9 memiliki komposisi jenis pakan yang hampir sama dengan plot lainnya walaupun hanya terdapat satu dan dua jenis yang sama. Hal ini berarti bahwa komposisi jenis hampir merata pada setiap plot.

Faktor yang menyebabkan perbedaan komposisi jenis pada setiap plot diperkirakan karena pada pengamatan kukang jawa juga sering terlihat memanfaatkan pohon kiara selain sebagai pohon pakan, pohon tersebut juga di jadikan sebagai tempat bermain dan berlindung. Pada pengamatan plot 4 dalam penelitian ini kukang jawa terihat memanfaatkan pohon tangkil sebagai pohon untuk tidur. Pada plot 5 terlihat ada kesamaan pohon pakan pada plort 1 yaitu bambu dan pada plot 3 yaitu kiara, hal ini menunjukan bahwa pohon bambu dan pohon kiara paling mendominansi yang ada pada lokasi penelitian dan yang sering dimanfaatkan oleh kukang jawa. 
Pada plot 6 terlihat ada kesamaan pohon pakan pada plot 1 dan 5 yaitu pohon bambu, pada plot 3 dan 5 yaitu pohon kiara dan pada plot 2 dan 4 yaitu pohon kaliandra, hal ini menunjukan untuk pohon pakan yang sama pada setiap plotnya hampir merata meskipun tidak semua vegetasi sama. Pada plot 7 terlihat hampir semua pohon pakan mendominansi pada setiap plot meskipun tidak semua, seperti pada plot 1, 5, dan 7 yaitu pohon aren, pada plot 1, 5, 6 dan 7 yaitu pohon bambu, pada plot 2, 6, dan 7 yaitu pohon kaliandra dan pada plot 3, 5, 6 dan 7 yaitu pohon kiara. Hal ini menunjukan bahwa pada setiap plot yang paling mendominansi yaitu pohon bambu dan pohon kiara yang sering terlihat di lokasi penelitian. Faktor yang menyebabkan berbedannya pohon pakan pada plot 1 sampai 8 karena tidak ada regenerasi pada pohon pakan yang sama, meskipun begitu pada dasarnya kukang jawa menyukai pohon pakan tersebut dan beberapa diantaranya ada yang mendominansi seperti bambu sebagai sarangnya.

\section{Bagian yang Dimakan}

Terlihat pada Tabel 2 jenis pakan kukang yang paling mendominasi atau yang paling banyak ditemukan dan dimanfaatkan oleh kukang yaitu bambu dan pohon kiara dengan bagian yang dimakan berupa daun, bunga, buah dan pucuk. Jenis bambu yang tersebar pada blok 1, 5, 6, 7, 8, dan 9. Bagian yang dimakan dari jenis bambu ini adalah daun dan pucuk. Bambu juga dimanfaatkan oleh kukang jawa sebagai aktivitas hariannya seperti tempat bermain dan beristirahat, sedangkan untuk sarangnya sering terlihat pada pohon bambu, karena pohon bambu yang rimbun dan rapat sehingga memungkinkan kukang jawa untuk berlindung dari mangsanya seperti ular, elang dan macan dahan. Winarti et.al. (2003), Widarteti (2008), dan Widarteti (2012) juga menambahkan bahwa preferensi atau tingkat kesukaan dari karakteristik habitat kukang jawa yaitu vegetasi bambu yang ditemukan di wilayah Sumedang dan Tasikmalaya. Hal ini karena bambu dapat dijadikan sebagai tempat berlindung/istirahat.

Widarteti (2010) juga menambahkan bahwa kukang jawa ditemukan pada beberapa tipe vegetasi, yaitu: 1) hutan sekunder campuran pinus, bambu, mindi, dan tangkil; 2) hutan sekunder dan primer yang banyak terdapat buah-buahan; 3) lahan perkebunan dan pertanian masyarakat yang didominasi oleh bambu, puspa; 4) lahan idustri seperti perhutani yang diatanami dengan palawija, buah-buahan, mahoni, dan meranti; 5) hutan produksi dengan vegetasi campuran anatara lain cengkeh, aren, mahoni, manii, dan salak. Hal ini juga sama dengan kondisi kukang jawa di TWA Gunung Tampomas bahwa kukang jawa banyak ditemukan pada blok hutan campuran yang berbatasan dengan lahan/kebun masyarakat dan terlihat juga pada Tabel 1 terdapat 6 jenis yang dimakan/dimanfaatkan oleh kukang jawa berupa buah-buahan. 
Jenis pakan yang paling banyak dimakan juga kiara, aren dan bisoro. Bagian yang paling banyak dimakan dari ketiga jenis ini adalah buah, karena memang kukang jawa di lokasi lain juga paling banyak ditemukan di perkebunan masyarakat untuk mencari buah-buahan (Winarti et.al., 2003; Widarteti, 2008; Widarteti, 2012). Jenis pakan lainnya yang dimakan berupa buah, yaitu huru leueur, kilaki, dan teureup. Jenis pakan yang dimakan bagian pucuk adalah bambu, hamirung, kitambaga, kibanen, kisampang, nangsi, sempur, dan tangkil. Jenis pakan yang dimakan berupa daun hamper pada semua jenis, sedangkan bagian yang dimakan berupa bunga hanya pada jenis sempur.

Jenis pakan berupa hewan sebagai pemenuhan proteinnya tidak terlihat pada pengamatan ini karena pada waktu penelitian pada musim hujan sehingga sulitnya untuk melihat kukang jawa saat akfitas makan. Padahal jika dilihat dari beberapa referensi bahwa hampir seluruh dari keluarga kukang merupakang omnivore, yaitu memakan nektar, bunga, serangga, getah, dan vertebrata (Wirdateti, 2012; Nekaris \& Starr, 2015). Begitu juga dengan Nekaris et al. (2010), Winarti (2011), RodeMargono et al. (2014) menyatakan bahwa seluruh anggota family dari Lorisidae menjadikan getah sebagai pakan utama, dan menjadikan keluarga Fabaceae, Arecaceae, dan Moraceae sebagai sumber getah. Oleh karena itu, tidak ditemukannya perilaku makan kukang jawa dari serangga, nektar, dan getah diperkirakan karena waktu pengamatan pada musim hujan sehingga kukang jaawa lebih banyak berlindung di atas pohon. Karena pada saat musim penghujan kukang jarang keluar dari pohon tidur mereka dan akan kembali aktif setelah 30 menit hujan reda. Seperti halnya diuangkapkan oleh Angeliza (2014) bahwa perilaku kukang jawa berdiam diri biasanya dipengaruhi oleh curah hujan tinggi, dan terang bulan.

\section{KESIMPULAN}

Terdapat 17 spesies sebagai sumber pakan kukang jawa, yaitu aren (Arenga pinnata), bamboo (Bambusa vulgaris), bisoro (Ficus leificarva), hamirung (Vernonia arborea), huru leueur (Phoebe excelsa), kaliandra (Calliandra calotyrsus), kiteja (Parinari sumatrana), kitembaga (Eugenia cuprea), kibanen (Criyteronia paniculata), kiara (Ficus altisima), kipait (Tithonia diversifolia), kisampang (Evodia latifolia), kilaki (Adina fagifolia), nangsi (Villebrunea rubescens), sempur (Dillenia indica), teureup (Artocarpus elastic), dan tangkil (Gnetum gnenom). Bagian yang dimakan berupa buah, daun, pucuk, dan bunga.

\section{DAFTAR PUSTAKA}

Alikodra, H.S. (2002). Pengelolaan Satwa Liar Jilid I. Bogor: Yayasan Penerbit Fakultas Kehutanan (YPFK). 
Angeliza, R. (2014). Perilaku Harian Kukang Jawa (Nycticebus javanicus Geoffroy 182) di Taman Nasional Gunung Halimun Salak (TNGHS) Jawa Barat. (Skripsi). FMIPA Institut Pertanian Bogor, Bogor.

Arismayanti, E. (2014). Wilayah Jelajah dan Penggunaan Ruang Harian Kukang Jawa (Nycticebus javanicus) di Taman Nasional Halimun Salak, Jawa Barat [Skripsi] . Institut Pertanian Bogor.

[Dephut] Departemen Kehutanan RI. (1990). Undang-undang No 5 tahun 1990 tentang Konservasi Sumber Daya Alam Hayati dan Ekosistemnya. Jakarta: Pemerintah Republik Indonesia.

[Dephut] Departemen Kehutanan RI. (1999). Peraturan Pemerintah No 7 tahun 1999 tentang Pengawetan Jenis Tumbuhan dan Satwa. Jakarta: Pemerintah Republik Indonesia.

Fagen. (1998). Population Effects of Habitat change - A quantitative Assesment. Journal Wildlife Manage 52 41-46.

Groves, C. (2001). Primate Taxonomy. Washington DC(US): Smithsonian Institusion Press.

Indriyanto. (2006). Ekologi Hutan. Jakarta: PT Bumi Aksara

Irwanto. (2006). Kapasitas Untuk Mendukung Pertumbuhan Populasi Suatu Organisme Disebut Daya Dukung Habitat.

Napier, JR dan Napier, PH. (1967). A Handbook of Living Primates. New York Academic Press.

Napier, JR dan Napier, PH. (1985). the Natural History of the Primates. Cambridge: The MIT Press.

Nekaris, K. A. I. \& Starr, C. R. (2015). Conservation and ecology of the neglected slow loris: Priorities and prospects. Endangered Species Research, 28, 87-95.

Nekaris, K. A. I., Starr, C. R., Collins, R. L., \& Wilson, A. (2010). Comparative ecology of exudate feeding by lorises (Nycticebus, Loris) and pottos (Perodicticus, Arctocebus). In: Burrows A \& Nash L. Edition The Evolution of Exudativory in Primates (pp. 155-168). Developments in Primatology: Progress and Prospects. New York, USA: Springer.

Pambudi, JAA. (2008). Studi Populasi, Perilaku, dan Ekologi Kukang Jawa (Nycticebus javanicus E. Geoffroy, 1812) di Hutan Bodogol Taman Nasional Gunung Gede Pangrango Jawa Barat. Tesis. Universitas Indonesia, Jakarta.

Rode-Margono, E. J., Nijman, V., Wirdateti, \& Nekaris, K. A. I. (2014). Ethology of the critically endangered javan slow loris Nycticebus javanicus E. Geoffroy SaintHilaire in West Java. Asian Primates Journal, 4(2), 27-41.

Romdhoni, H., R. Komala, M. Sigaud, K.A.I. Nekaris, A. Sedayu. (2018). Studi Pakan Kukang Jawa (Nycticebus javanicus Goeffroy, 1812) di Talun Desa Cipaganti, Garut, Jawa Barat. Journal of Biology, 11(1), 2018, 9-15. DOI: http://dx.doi.org/10.15408/kauniyah.v11i1. 4914

Resort XIII Sumedang.Profil Taman Wisata Alam Gunung Tampomas dan Cagar Alam Gunung Jagat. 
Rowe, N. (1996). the Pictorial Guide to the Living Primates. New York: Pogonian Press.

Sukarsono. (2012). Ekologi Hewan. Malang: Universitas Muhammadiyah Malang

Winarti 1.(2003). Distribusi dan Struktur Vegetasi Habitat Kukang (Nycticebus coucang Boddaert, 1785) di desa Marga Mekar, Kecamatan Sumedang Selatan, Jawa Barat. (Skripsi). Unversitas Pajajaran, Sumedang.

Winarti, I. (2011). Habitat, populasi, dan seberan kukang Jawa (Nycticebus javanicus Geoffroy 1812) di talun Tasikmalaya dan Ciamis. (Tesis). Sekolah Pascasarjana, Bogor.

Wirdateti, H. Dahrudin. (2008). Sebaran dan habitat kukang (Nycticebus coucang javanicusy di hutan rakyat dan lahan perkebunan Kabupaten Ciamis, Jawa barat. Laporan Teknik Puslit Biologi-L1PI. DIPA 2008. P. 1425-1433.

Widarteti, Hadi Dahrudin, Alex Sumadijaya. (2010). Sebaran dan Habitat Kukang Jawa (Nycticebus javanicus) di Lahan Pertanian (Hutan Rakyat) Wilayah Kabupaten Lebak (Banten) dan Gunung Salak (Jawa Barat). Zoo Indonesia 20(1). 17-25.

Widarteti. (2012). Sebaran dan Habitat Kukang Jawa (Nycticebus javanicus) di Area Perkebunan Sayur Gunung Papandayan, Kabupaten Garut. Berita Biologi 11(1): 111-118. 